\title{
Desgaste interproximal e suas implicações clínicas
}

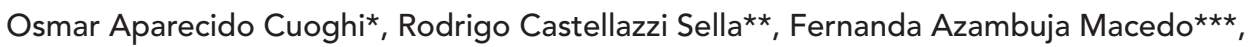

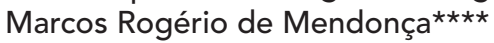

\begin{abstract}
Resumo
Introdução: o alinhamento dentário correto, bem como sua estabilidade, representam objetivos importantes do tratamento ortodôntico. $\mathrm{O}$ apinhamento na região anterior é uma anomalia de posição dentária comum e para obter sua correção as opções clínicas disponíveis para o ortodontista são as extrações dentárias, a expansão do arco dentário ou os desgastes interproximais. Os desgastes freqüentemente são indicados, mas existem questionamentos quanto às indicações, técnicas e condições pré e pós-tratamento. Objetivo: o objetivo deste artigo é apresentar uma discussão, embasada na literatura pertinente, dos principais fatores envolvidos com este procedimento clínico.
\end{abstract}

Palavras-chave: Desgaste interproximal. Apinhamento. Movimentação dentária.

\section{INTRODUÇÃO}

O apinhamento dentário está presente na maioria das más oclusões, requerendo do profissional um conhecimento amplo sobre o diagnóstico e plano de tratamento. De acordo com sua severidade, existem modos diferentes de tratamento, como a distalização de molares, as extrações, as expansões dos arcos dentários e os desgastes interproximais. Os desgastes dentários referem-se à diminuição das dimensões dentárias mesiodistais com objetivo de corrigir apinhamentos suaves ou moderados, bem como eliminar a desproporção natural de tamanho dentário entre os arcos, e requerem o conhecimento de vários aspectos clínicos para serem realizados $s^{4,7,10,14,15,17,18,19}$.

A nomenclatura pertinente envolve os termos recontorno ou reaproximação dentária, que suge- rem exatamente o tratamento ortodôntico sem extrações, uma vez que a característica primordial da má oclusão é a discrepância de modelos negativa, sendo o tamanho dentário o maior contribuinte para o problema ${ }^{21,25}$. A principal vantagem deste procedimento é a redução do tempo de tratamento, pois a quantidade de esmalte desgastado normalmente corresponde ao espaço requerido.

A Ortodontia contemporânea vem usufruindo intensivamente deste procedimento, o que o torna cada vez mais freqüente no cotidiano clínico ${ }^{18,19,20}$. Entretanto, muitas são as dúvidas quanto ao nível de apinhamento que pode ser corrigido, quantidade de desgaste do esmalte e sua qualidade após a terapia, envolvimento pulpar e periodontal, materiais utilizados e estabilidade em longo prazo, de modo que o desgaste interproximal constitui um

\footnotetext{
* Professor Assistente Doutor do Departamento de Odontologia Infantil e Social, Disciplina de Ortodontia Preventiva, da Faculdade de Odontologia de Araçatuba - UNESP.

** Mestre em Ortodontia pelo Programa de Pós-Graduação em Odontologia da Faculdade de Odontologia de Araçatuba - UNESP. Doutorando em Ortodontia pelo Programa de Pós-Graduação em Odontologia da Faculdade de Odontologia de Araçatuba - UNESP.

*** Mestre em Ortodontia pelo Programa de Pós-Graduação em Odontologia da Faculdade de Odontologia de Araçatuba - UNESP. **** Professor Assistente Doutor do Departamento de Odontologia Infantil e Social, Disciplina de Ortodontia Preventiva, da Faculdade de Odontologia de Araçatuba - UNESP.
} 
assunto de suma importância e não completamente conhecido.

Porém, é importante deixar bem claro que os desgastes interproximais são utilizados para a redução da dimensão dentária, pois este é o fator a ser corrigido; quando a discrepância de modelos tem como fator principal o aumento do espaço presente, outros procedimentos têm melhor indicação. $\mathrm{O}$ clínico deve estar atento para não oferecer o tratamento equivocado ou até mesmo associar dois métodos de tratamento sem o correto entendimento do que deve ser corrigido.

Desta forma, este artigo tem como propósito discutir os fatores relacionados com o procedimento conhecido por desgaste interproximal, exemplificar os principais métodos de aplicação e apresentar a utilização desta técnica no tratamento ortodôntico.

\section{REVISÃO DA LITERATURA}

O desgaste interproximal tem sido documentado ao longo dos anos e teve destaque a partir da década de 80 , quando Sheridan ${ }^{17,18}$, Sheridan e Ledoux ${ }^{19}$ escreveram seus artigos clássicos. Entretanto, este procedimento foi pouco utilizado antes do advento da colagem direta, pois o tratamento era realizado com a bandagem de todos os dentes, impossibilitando a realização desta técnica para obtenção de espaço ${ }^{17}$. Atualmente, os desgastes tornaram-se comuns, por meio do estabelecimento de uma alteração da anatomia dos contatos proximais, tanto para eliminar problemas de apinhamento e discrepância de tamanho dentário, quanto para aumentar a estabilidade dos arcos dentários. Este tipo de intervenção parece originar-se de dados colhidos de aborígines préhistóricos que, freqüentemente, exibiam desgastes dentários oclusais e proximais, com arcos estáveis e sem a presença de apinhamento ${ }^{5}$.

\section{Indicações e quantidade de desgaste do esmalte}

O procedimento de desgaste interproximal de dentes anteriores para correção de apinhamento está se tornando cada vez mais conhecido. Entretanto, é extremamente importante entender que esta abordagem não está indicada para a correção de casos de apinhamento severo, mas um suplemento para eliminação de apinhamentos suaves e moderados envolvendo muitos casos considerados limítrofes para o tratamento ortodôntico, proporcionando um resultado estético mais favorável.

Tradicionalmente, o desgaste de esmalte nas regiões interproximais foi idealizado para o tratamento de casos com discrepâncias entre as larguras dos dentes superiores e inferiores. Esta filosofia foi brilhantemente descrita por Bolton ${ }^{4}$ em seu artigo clássico de 1958, que relata a desarmonia de tamanho dentário e sua relação para a análise e tratamento das más oclusões. Estudos subseqüentes, como os de Crosby, Alexander ${ }^{6}$ e Freeman et al. ${ }^{9}$, demonstraram que aproximadamente 20\% dos pacientes apresentam discrepância de tamanho dentário, decorrente de um excesso de massa dentária no arco inferior.

Em um artigo clássico de 1980 relacionando os fatores envolvidos com a oclusão do segmento anterior, Tuverson ${ }^{21}$ inferiu que a redução de esmalte de $0,3 \mathrm{~mm}$ para os incisivos inferiores e $0,4 \mathrm{~mm}$ para os caninos inferiores pode ser realizada sem prejudicar a vitalidade dentária. Radiograficamente, existe esmalte suficiente para permitir o desgaste dentário sem comprometimento da face proximal. Enfatizou que a opção pelo desgaste dentário seria a alternativa mais indicada para casos limítrofes de extração.

Sheridan ${ }^{18}$ afirmou que os desgastes interproximais podem ser indicados para tratar indivíduos que apresentem discrepâncias de modelos de 4 a $8 \mathrm{~mm}$, evidenciando-se uma alternativa para o tratamento de casos com discrepância negativa de modelos.

O desgaste pode ser realizado em até metade da espessura do esmalte interproximal, o que segundo Sheridan ${ }^{17}$ corresponde a aproximadamente $0,8 \mathrm{~mm}$ em cada face dos dentes posteriores e 
0,5 $\mathrm{mm}$ dos dentes anteriores de ambos os arcos, permitindo um ganho de até $8,9 \mathrm{~mm}$ de espaço se o desgaste for realizado a partir da mesial dos primeiros molares.

Em 1998, Stroud et al. ${ }^{20}$ quantificaram o desgaste proximal na região posterior do arco dentário inferior. Por meio de radiografias interproximais digitalizadas, a espessura do esmalte e da dentina de pré-molares e primeiros e segundos molares inferiores foi medida sobre o plano que representava o maior diâmetro mesiodistal de cada dente. Conforme o estudo, existem aproximadamente $10 \mathrm{~mm}$ de esmalte na região posterior ( 2 pré-molares e 2 molares) de cada hemiarco. Considerando-se 50\% de redução, estes dentes são capazes de promover $5 \mathrm{~mm}$ de espaço em cada hemiarco, o que totaliza $10 \mathrm{~mm}$ de espaço adicional para o tratamento ortodôntico no arco inferior. Não foram detectadas diferenças entre os gêneros, entretanto os autores julgaram interessante destacar que o esmalte nos segundos molares apresentou-se significativamente mais espesso $(0,3$ a $0,4 \mathrm{~mm})$ em relação aos pré-molares. Salientaram ainda que o desgaste interproximal é bem indicado para discrepâncias de arco menores que a soma dos diâmetros mesiodistais de dois pré-molares. Quando os $15 \mathrm{~mm}$ de comprimento de arco obtidos por meio de extrações representam mais do que o necessário para solucionar a discrepância de modelos negativa, este procedimento constitui uma opção mais conservadora, que permite ao ortodontista melhor controle de espaço. Os autores afirmaram que este tipo de terapia deve ser realizado apenas nos casos com apinhamento dentário suave, boa higiene bucal e relação de molares Classe I com perfil equilibrado. Além disso, este procedimento pode ser utilizado em casos de Classe II dentoalveolar ou discrepâncias de tamanhos dentários de Bolton, regularizando os níveis de trespasse horizontal e vertical.

Com relação aos caninos, o ideal é que seja avaliada a relação de intercuspidação posterior. Se a oclusão apresentar características de normalidade, os caninos não devem ser desgastados, para que ocorra a manutenção da relação adequada Por outro lado, nos casos de Classe II e Classe III, os caninos inferiores podem ser desgastados, respectivamente, nas faces mesiais e distais. Para os caninos superiores, as regiões mais indicadas para os desgastes são as distais nos casos de Classe II e mesiais nos casos de Classe III.

Barrer $^{3}$ informou que tratamentos que necessitam de até 2,5mm de espaço respondem bem à técnica de desgaste, todavia, discrepâncias maiores que esta, freqüentemente, requerem extrações.

Dipaolo e Boruchov ${ }^{7}$ destacaram a importância da mensuração do esmalte interproximal e da largura da raiz em relação à coroa, estabelecendo a radiografia periapical como método de avaliação. Ficou instituído que o limite do desgaste deve ser a metade do esmalte interproximal e a coroa não deve ser desgastada além da largura da raiz, o que impediria o fechamento do espaço e promoveria condições propícias para o desenvolvimento de problemas periodontais.

Contudo, Artun et al. ${ }^{2}$ analisaram a condição periodontal de áreas que apresentavam proximidade entre as raízes dentárias e verificaram que, ao contrário do que afirmaram Diapolo e Boruchov ${ }^{7}$, os dentes anteriores não apresentaram maior susceptibilidade aos problemas periodontais quando suas raízes estão mais próximas.

Segundo Harfin ${ }^{10}$, o desgaste pode ser realizado nos casos que exibem a má oclusão de Classe I, quando a fase de crescimento já cessou, com apinhamento de até $3 \mathrm{~mm}$ no arco inferior e $4 \mathrm{~mm}$ no arco superior. A autora destacou que esta técnica proporciona resultados clínicos satisfatórios quanto ao alinhamento dentário, com o mínimo de alteração no perfil e sem expansão no arco, evita extrações, promove resultados estáveis e elimina espaços triangulares nas regiões cervicais em pacientes adultos. Além disso, mencionou que este procedimento está contra-indicado em pacientes com má higienização (pois pode aumentar o risco de cáries), em pacientes com gengivite e em pacientes que ainda se encontram na fase de crescimento. 
Com o propósito de examinar a estabilidade em longo prazo do alinhamento dos incisivos inferiores sem o uso de retentores, Aasen e Espeland ${ }^{1}$, em 2005, utilizaram uma amostra de 56 pacientes tratados conforme um protocolo que incluiu a sobrecorreção de dentes que apresentavam giroversão e redução de esmalte das superfícies proximais na região ânteroinferior. Houve uma preocupação quanto à manutenção da forma do arco dentário, evitando expansão lateral e vestibularização dos incisivos. Foram obtidos modelos de estudo iniciais, finais e com 3 anos de pós-tratamento. $\mathrm{O}$ alinhamento dos incisivos inferiores foi registrado por meio do índice de irregularidade de Little ${ }^{12}$. A distância intercaninos e a soma das larguras mesiodistais dos incisivos inferiores e caninos também foram medidas. $O$ total de esmalte removido, advogado por estes autores, nas superfícies proximais dos dentes ântero-inferiores variou de 0,3 a $5 \mathrm{~mm}(1,9 \mathrm{~mm}$ em média). O aumento médio de 0,6 no índice de irregularidade de Little, da fase final à fase de 3 anos pós-tratamento, indicou estabilidade satisfatória. Em 45\% dos pacientes, a mudança no valor do índice de irregularidade durante este período foi menor que 0,5 , indicando que o método de tratamento apresentado pode ser considerado uma estratégia alternativa à instalação da contenção inferior, para manter a estabilidade do alinhamento dos incisivos inferiores.

Considerando que a diminuição de $50 \%$ do esmalte dentário resguarda uma espessura de esmalte aceitável biologicamente, este procedimento constitui um método de tratamento que pode ser aplicado nos casos de apinhamentos suaves a moderados, ou ainda, para correção de desproporções dentárias dos casos que apresentam discrepância de Bolton.

\section{Qualidade do esmalte após o desgaste}

O desgaste do esmalte proporciona alguns efeitos indesejáveis. Ao realizar este procedimento, Radlanski $^{14}$ explicou que são criados sulcos, destacando a impossibilidade de eliminação destes, mesmo quando é realizado o polimento.

Considerando as inúmeras tentativas de eliminação dos sulcos provocados pelos desgastes, Zachrisson ${ }^{25}$ destacou que superfícies lisas podem ser produzidas com discos para polimento. Conforme o disco de lixa vem se desgastando durante o procedimento, age como um instrumento de polimento, descartando a necessidade de polimento adicional.

Sheridan e Ledoux ${ }^{19}$ informaram que a realização de desgaste com brocas associadas à micromotores e selantes pode proporcionar um menor risco de cáries interproximais, por meio do selamento e suavização dos sulcos gerados durante o procedimento de desgaste.

Entretanto, El-Mangoury et al. ${ }^{8}$ demonstraram que as superfícies desgastadas não são mais susceptíveis a cáries, quando comparadas com superfícies normais. Não foi utilizado selante, como sugerem Sheridan e Ledoux ${ }^{19}$, pois para os autores a aplicação de selantes interfere na remineralização do esmalte, que ocorre 9 meses após a realização do procedimento. Todavia, a aplicação tópica de flúor foi estabelecida como um procedimento valioso para proteção contra cáries.

Investigando as alterações microscópicas sobre a polpa e a dentina após o desgaste de esmalte, Zachrisson e Mjör ${ }^{24}$ relataram que a superfície de esmalte submetida ao desgaste com instrumentos diamantados apresentava irregularidades pronunciadas, de acordo com a granulação da lixa ou broca utilizada.

Em 1999, Zhong et al. ${ }^{26}$ criaram um protocolo do procedimento de polimento, que deve ser realizado com discos Sof-Lex (3M) fino e ultra-fino, por 40 segundos cada. Discordes das afirmações de Radlansk et al. ${ }^{14}$, que defenderam que a superfície polida dessa forma apresenta-se mais lisa que o esmalte original.

Comparando métodos de desgaste e polimento, Piacentini e Sfondrini ${ }^{13}$ elucidaram que a superfície de esmalte com maior lisura foi aquela submetida ao desgaste com broca carbide de tungstênio 
com 8 lâminas retas, com posterior polimento por meio de discos Sof-Lex.

Sobre este aspecto, no estudo in vitro desenvolvido em 1994, Twesme et al..$^{22}$ observaram que o uso de gel fluoretado sobre o esmalte desgastado promoveu uma redução na penetração da lesão cariosa, porém, em menor grau quando comparado com a superfície não desgastada.

Em 1992, Joseph et al. ${ }^{11}$ aferiram o efeito de uma solução sintética calcificadora (concentração de cálcio de $1 \mathrm{~mol} / \mathrm{l}$ ) sobre o esmalte desmineralizado. Após a aplicação de ácido fosfórico durante 1 minuto sobre a face vestibular de 10 incisivos centrais, lavagem e secagem, aplicou-se duas camadas de verniz de unha sobre metade das faces vestibulares desmineralizadas e dividiuse a amostra aleatoriamente em dois grupos. $\mathrm{O}$ grupo I recebeu 1 hora de exposição à solução remineralizadora, continuamente agitada por uma máquina osciladora. O grupo II foi tratado com 10 exposições com 1 hora de duração cada. Os resultados mostraram marcante precipitação cristalina em 5 e 10 horas de exposição à solução. Levando-se em consideração que a remineralização artificial de superfícies de esmalte submetidas ao ataque ácido é possível por meio de soluções de cálcio-fluoreto, sugeriu-se a realização de desgastes mecânico-químicos, proporcionando a menor rugosidade superficial gerada em relação aos métodos mecânicos.

\section{Envolvimento pulpar e acúmulo de placa bacteriana}

Em 1966, Van Der Fehr e Steiness ${ }^{23}$ elucidaram que o desgaste dentário limitado ao esmalte não provoca alterações microscópicas na polpa ou na dentina. Os autores demonstraram que quando exposto ao meio bucal, o esmalte desgastado incorpora características próximas às do esmalte normal. Por outro lado, a análise microscópica da superfície do esmalte submetido ao desgaste exibiu irregularidades proporcionais à aspereza do instrumento (broca ou lixa). Esta condição produziu áreas com retenção de placa e regiões susceptíveis a cáries, com conseqüentes alterações dentinárias e pulpares. Entretanto, se a lisura superficial for atingida, este procedimento não se torna prejudicial.

Existem diferentes opiniões quanto aos resultados e estabelecimento de efeitos deletérios do desgaste do esmalte. Tuverson ${ }^{21}$ defende a idéia de que esta técnica deve ser seletivamente utilizada em pacientes com boa higiene bucal e baixa susceptibilidade a cáries. Desta forma, as indicações para utilização desta técnica podem estar comprometidas, pois não existem garantias de que a higiene bucal satisfatória será mantida ao longo da vida.

Em 1988, Radlanski et al. ${ }^{14}$ citaram que a predisposição a cáries interproximais e problemas periodontais, causada pelo desgaste interdentário, parece estar associada ao acúmulo de placa nos sulcos. Entretanto, o mesmo autor, em 1989, verificou a ausência de cáries e problemas periodontais, um ano após a realização dos desgastes interproximais com tiras de lixas.

Além disso, Rogers e Wagner ${ }^{16}$ mencionaram que a aplicação tópica de flúor é de valor clínico real para proteger a superfície do esmalte reduzido pelo desgaste. Enfatizaram que o desgaste deve ser realizado com irrigação abundante e, quando limitado ao esmalte, este não provoca alterações na polpa ou na dentina.

\section{Recursos utilizados para realização de desgastes interproximais}

Vários métodos são utilizados para realização do desgaste. Os mais citados são a lixa de aço para amálgama, a ponta diamantada montada em alta rotação, o disco de lixa unifacetado e as brocas de tungstênio multilaminadas com 8 lâminas retas.

Sheridan ${ }^{17}$ descreveu a técnica de desgaste com alta rotação, objetivando a remoção de esmalte, principalmente, na região distal de caninos, em decorrência da maior quantidade de esmalte. 
Salientou a necessidade de manutenção da forma original do ponto de contato. Para facilitar os procedimentos operatórios, foi recomendada a inclusão de um fio de aço 0,020" no espaço interproximal, evitando danos à gengiva, controlando a remoção e acabamento do esmalte e favorecendo a fluoretação tópica. O fio 0,020 " corresponde a um diâmetro de $0,5 \mathrm{~mm}$ e, uma vez que foi recomendada a redução de $50 \%$ do esmalte interproximal (aproximadamente $0,5 \mathrm{~mm}$ em cada face proximal dos dentes anteriores), este fio representa o parâmetro de controle para desgastar $0,5 \mathrm{~mm}$ de esmalte em cada uma das duas faces proximais que constituem o ponto de contato. Para realização dos desgastes, foi selecionada uma broca carbide tronco-cônica 699L que, conforme o autor, promove maior controle e eficiência de desgaste em relação às tiras de lixa, além de gerar menor quantidade de calor, devido aos jatos de água da caneta de alta rotação. A broca deve ser guiada paralelamente ao plano do fio em direção incisal ou oclusal. O procedimento é iniciado a partir da cervical, alternando de vestibular para lingual, de modo a reduzir o esmalte interproximal até que o fio possa ser movimentado livremente em direção incisal. Recomendou-se a finalização por meio de brocas carbide de acabamento, discos de polimento ou tiras de lixa para acabamento, de modo que as superfícies desgastadas sejam esculpidas, criando-se uma aparência anatômica natural.

Em 1987, o mesmo autor ${ }^{18}$ sugeriu certas alterações à técnica de desgaste realizada com alta rotação. Este procedimento deve ser precedido, primeiramente, pelo alinhamento dentário, que corrige angulações e rotações dentárias, movimentando os dentes até a obtenção de pontos de contato satisfatórios para a realização dos desgastes. Para melhor visualização e acesso à região interproximal, sugeriu-se a separação das superfícies interproximais por meio de molas de secção aberta. As últimas modificações dizem respeito à realização dos desgastes de forma seqüencial, de posterior para anterior, e ao estabelecimento de um contorno anatômico adequado com pontas diamantadas cônicas, especificação 135-EF, ultrafinas para acabamento.

Joseph et al. ${ }^{11}$ compararam, por meio de microscopia eletrônica de varredura, as diferenças exibidas pelo esmalte desgastado por métodos mecânicos e químicos. Sessenta dentes anteriores foram divididos em dois grupos. Os dentes incluídos no grupo I foram subdivididos em 5 subgrupos de 6 dentes, montados em um bloco de gesso com forma de arco da região anterior. Cada subgrupo foi desgastado por um dos seguintes métodos mecânicos abrasivos: (1) discos de lixa, (2) brocas carbide e diamantadas para acabamento, (3) brocas diamantadas para desgaste e para acabamento, (4) discos diamantados e tiras de lixa $3 \mathrm{M}$ ou (5) tiras de lixa de aço e tiras de lixa $3 \mathrm{M}$. Os dentes que constituíram o grupo II foram desgastados similarmente, com a exceção de que cada subgrupo foi submetido a um desgaste químico subseqüente, utilizando ácido fosfórico 37\% em conjunto com tiras 3M. A análise microscópica mostrou que os dentes desgastados pelos métodos mecânicos convencionais exibiram sulcos mais profundos e maior rugosidade em relação àqueles que receberam tratamento com técnica mecânica e química.

Zhong et al. ${ }^{26}$ defenderam o uso de dois discos Sof-Lex para eliminação das ranhuras provenientes dos desgastes. Estes discos devem apresentar granulação fina e ultrafina, sendo operados com micromotor em uma velocidade entre $200 \mathrm{e}$ 400rpm durante 40 segundos cada, o que produzirá uma temperatura em torno de $60^{\circ} \mathrm{C}$. Os autores salientaram a necessidade de se utilizar um disco para cada dente, pois sua superfície se deteriora com muita facilidade. O procedimento de acabamento e polimento realizado com discos proporciona maior segurança em relação às brocas, pois enquanto os menores diâmetros de brocas medem $0,18 \mathrm{~mm}$, os discos usados nessa técnica medem apenas $0,15 \mathrm{~mm}$.

Para realização dos desgastes, Harfin ${ }^{10}$ prefere 
tiras de lixa de aço aos discos e brocas. Ela defende que a lixa facilita a quantidade e a qualidade do esmalte removido, uma vez que as brocas removem o esmalte com maior rapidez. Por outro lado, as tiras de lixa proporcionam ranhuras maiores, facilitando o acúmulo de placa bacteriana. Para sanar este problema, a autora sugere que o acabamen-

\section{CASO CLÍNICO}
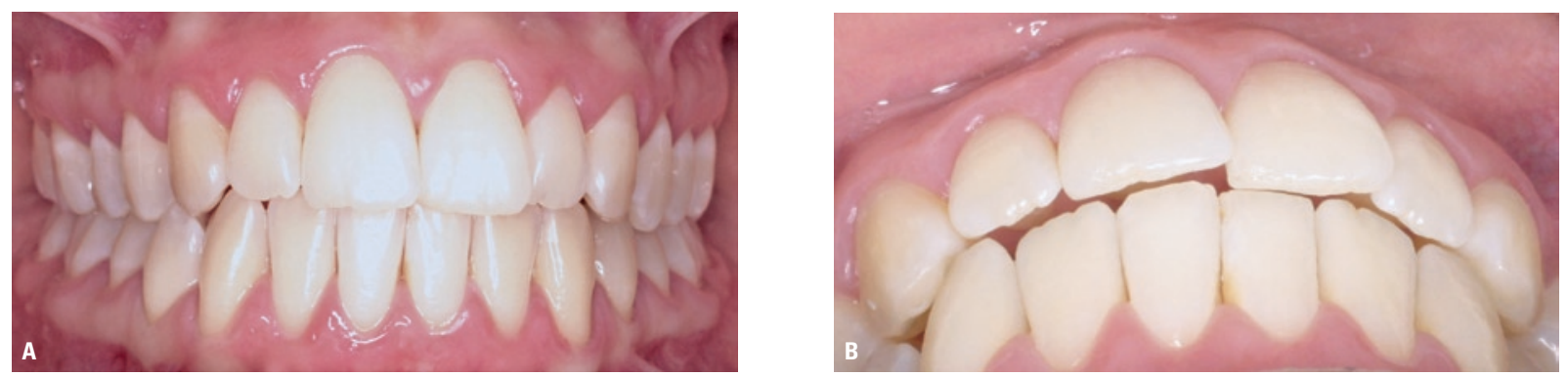

FIGURA 1 - Vistas intrabucais pré-tratamento: A) frontal e B) trespasse horizontal.

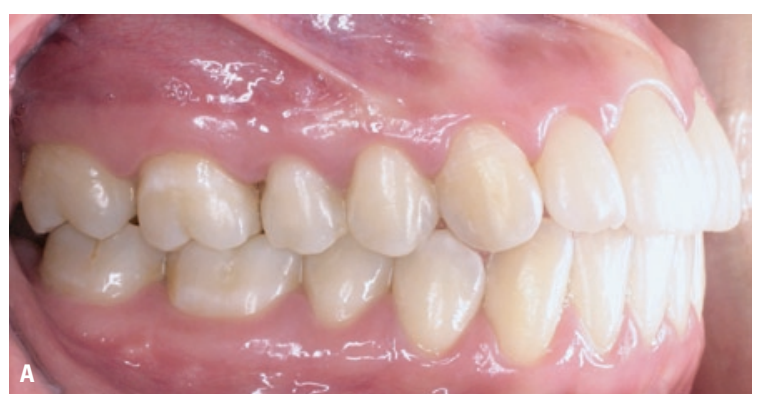

FIGURA 2 - Vistas laterais pré-tratamento: A) direita e B) esquerda.
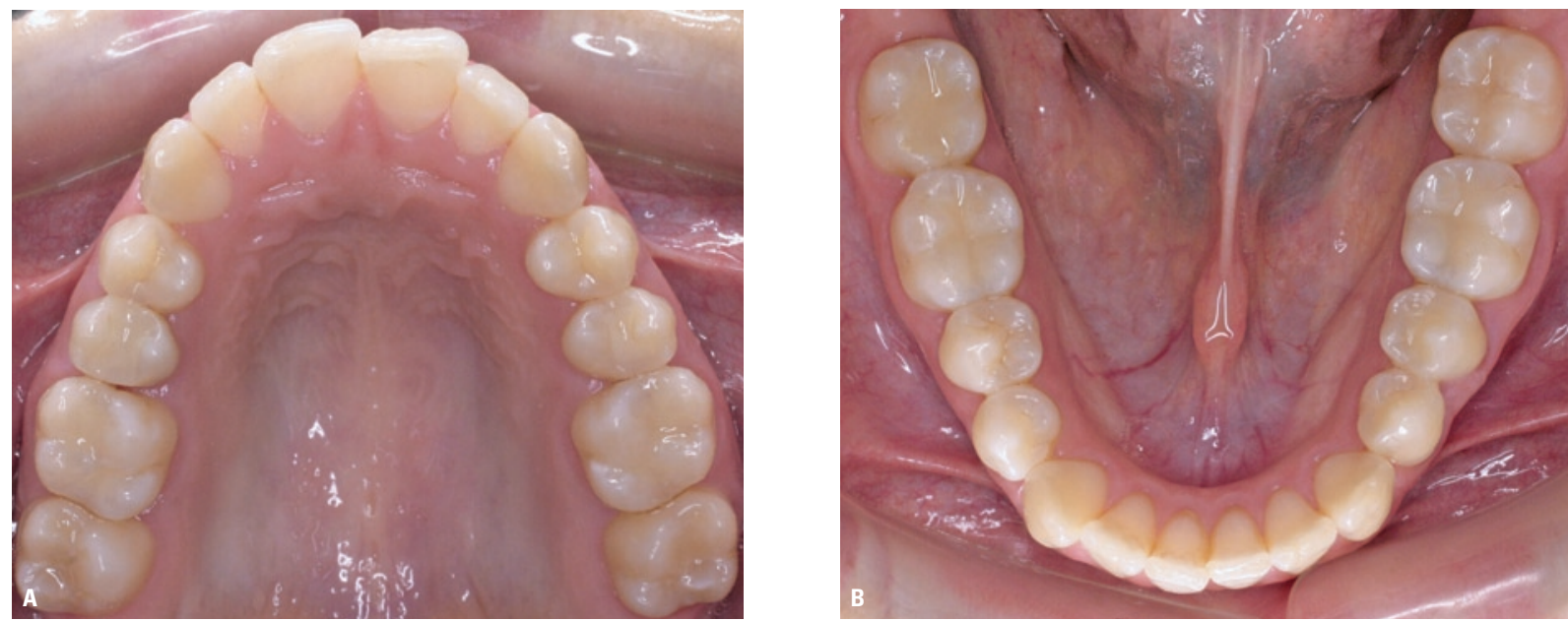

FIGURA 3 - A) Vista oclusal do arco superior, evidenciando a discreta discrepância dentoalveolar negativa e B) vista oclusal do arco inferior. 

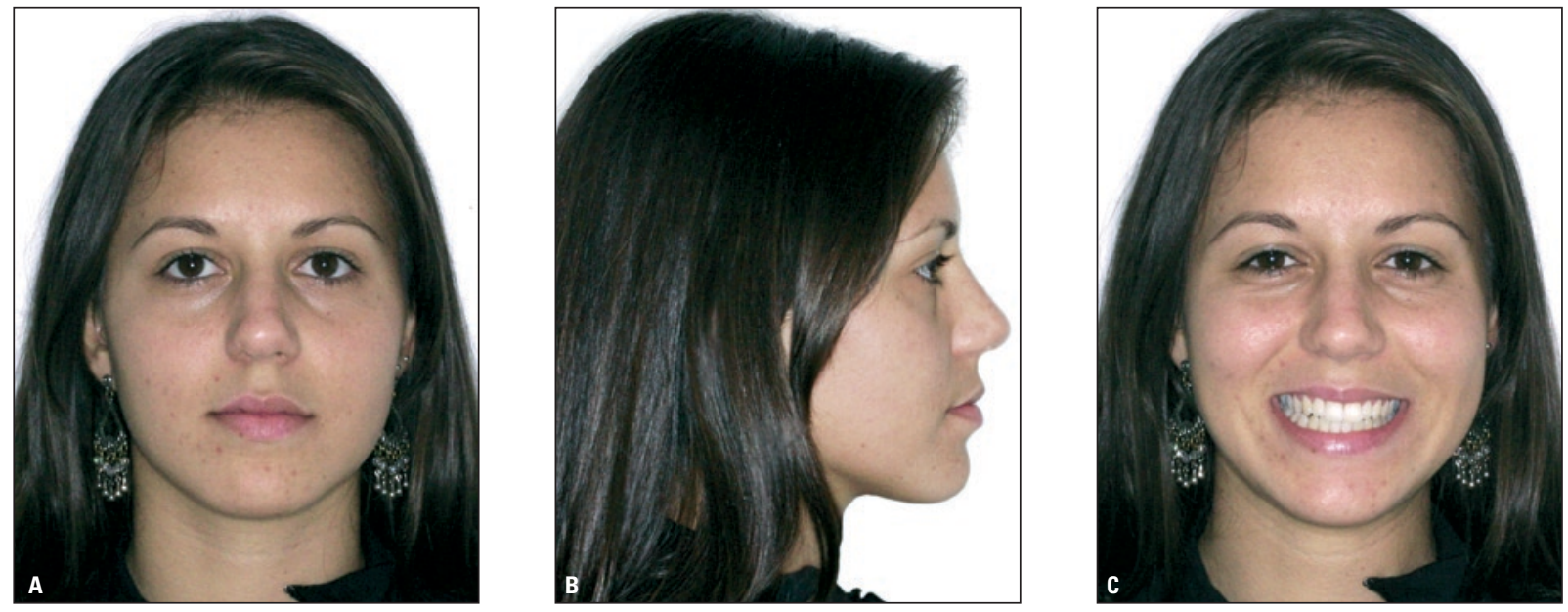

FIGURA 4 - Vistas faciais pré-tratamento: A) frontal, B) lateral e C) frontal sorrindo.

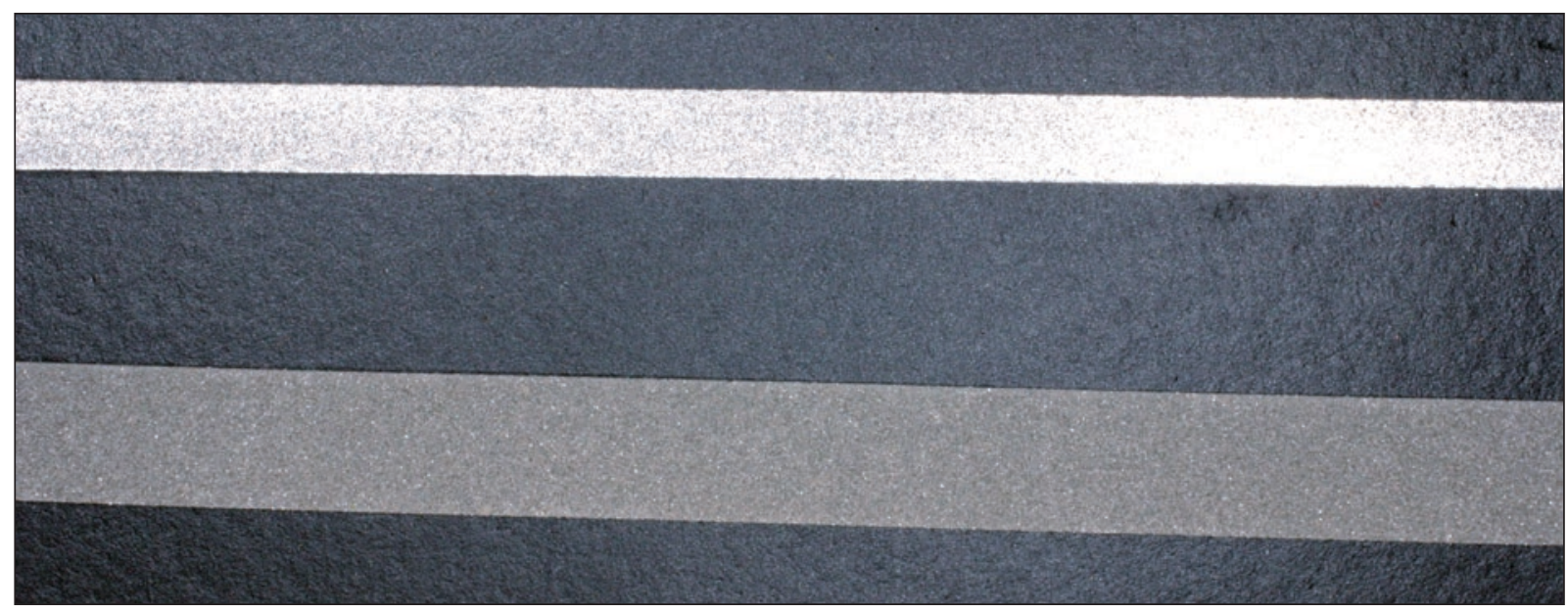

FIGURA 5 - Tiras de lixa de aço de 4mm e $6 \mathrm{~mm}$ de largura, utilizadas para realização dos desgastes interproximais iniciais.
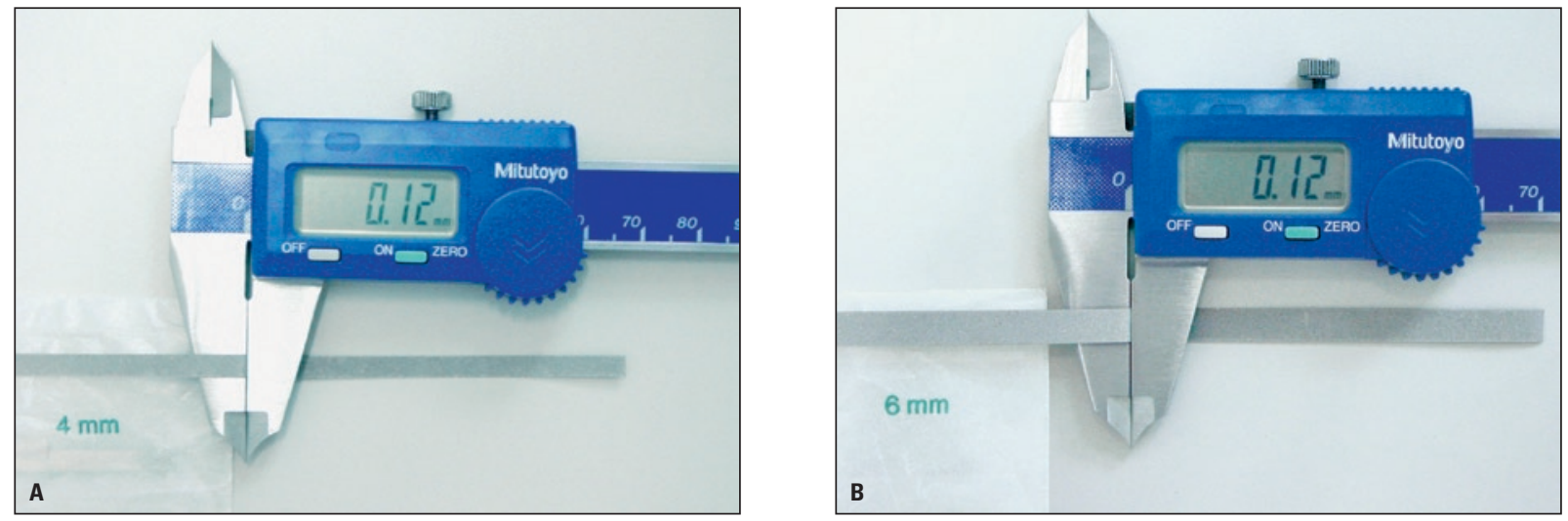

FIGURA 6 - Medição da espessura das tiras de lixa de aço de A) 4mm e B) $6 \mathrm{~mm}$. As tiras de lixa apresentam larguras diferentes, porém, espessuras iguais de $0,12 \mathrm{~mm}$. 


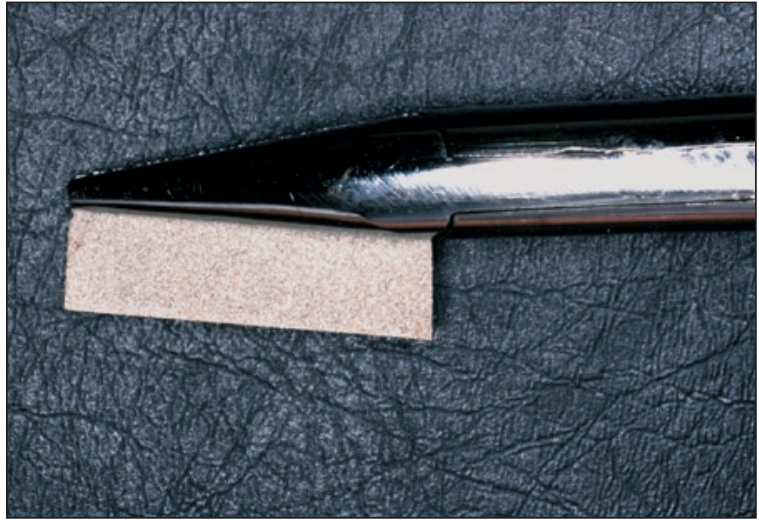

FIGURA 7 - Apreensão da tira de lixa de aço utilizando o porta-agulhas Mathieu.

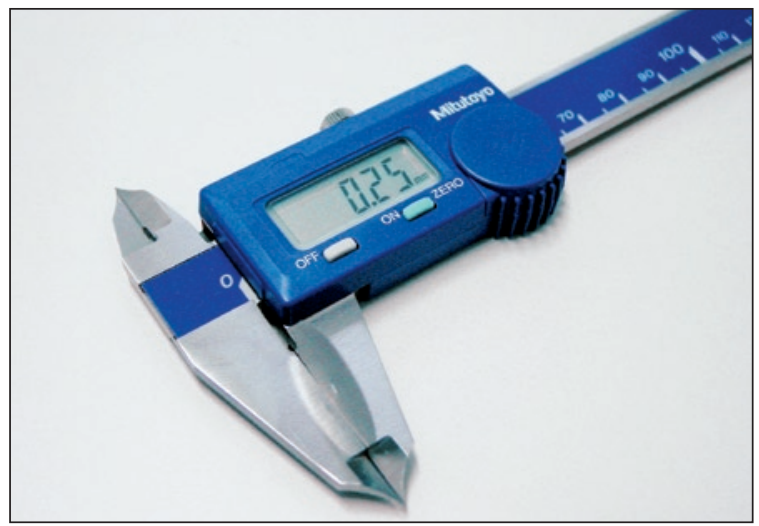

FIGURA 9 - Medição da espessura dos discos de lixa de aço, igual a 0,25mm.

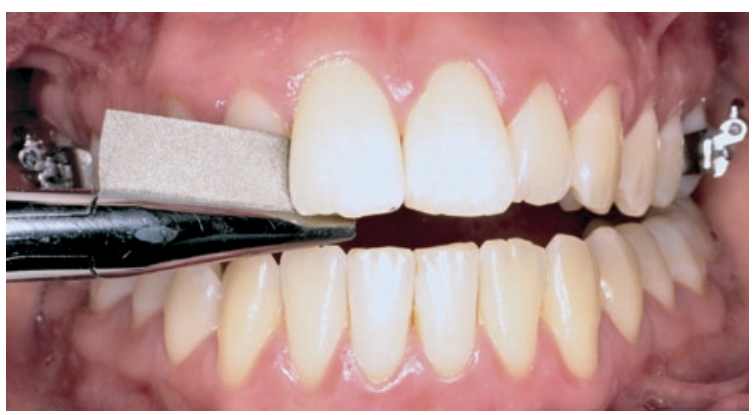

FIGURA 11 - Desgaste inicial na face distal do dente 11 com tira de lixa de $0,12 \mathrm{~mm}$ de espessura.

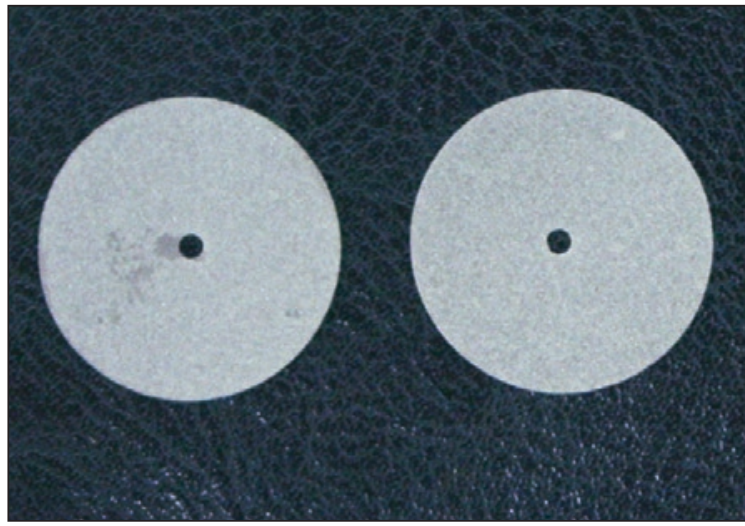

FIGURA 8 - Discos de lixa de aço utilizados para realização do desgaste interproximal, subseqüente às lixas de aço.

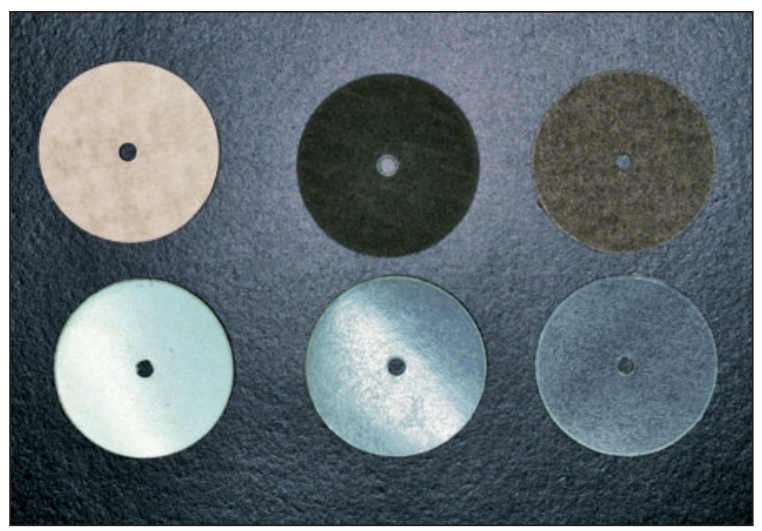

FIGURA 10 - Discos Sof-Lex (3M-UNITEK), granulação fina e ultra-fina, para polimento das superfícies desgastadas.

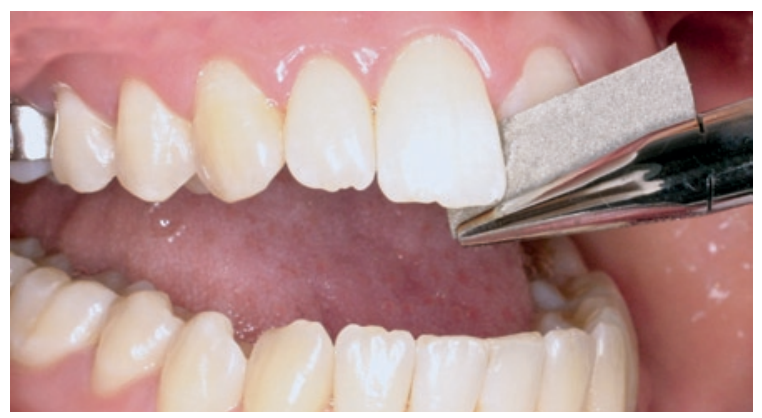

FIGURA 12 - Desgaste inicial na face mesial do dente 11 com tira de lixa de $0,12 \mathrm{~mm}$ de espessura. 


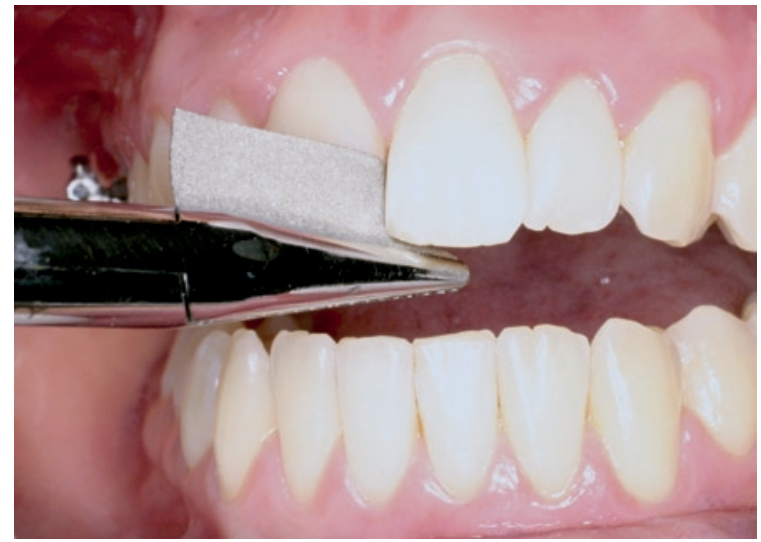

FIGURA 13 - Desgaste inicial na face mesial do dente 21 com tira de lixa de $0,12 \mathrm{~mm}$ de espessura.

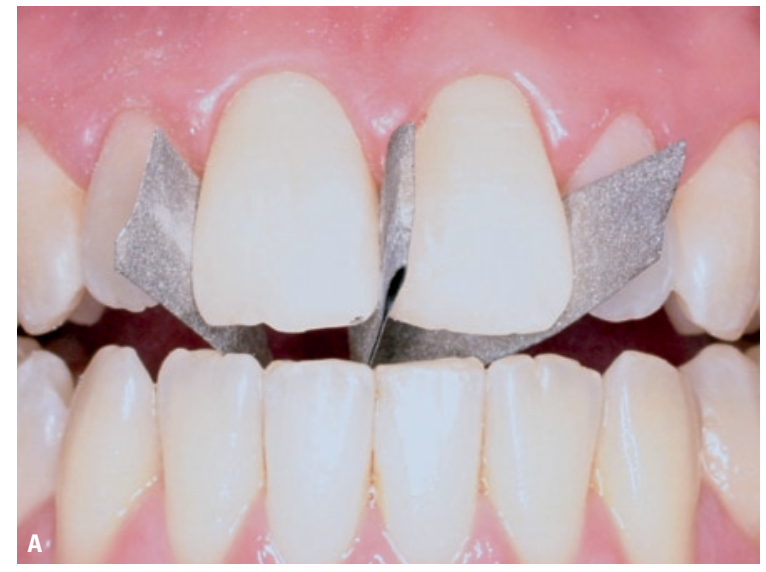

FIGURA 15 - Vistas A) frontal e B) oclusal, evidenciando o desgaste inicial total de aproximadamente 0,5mm, sendo 0,12mm para cada face proximal, exemplificado pelo posicionamento de uma tira de lixa de aço nas faces distais dos dentes 11 e 21 e duas tiras entre as faces mesiais destes dentes, uma para cada face mesial.

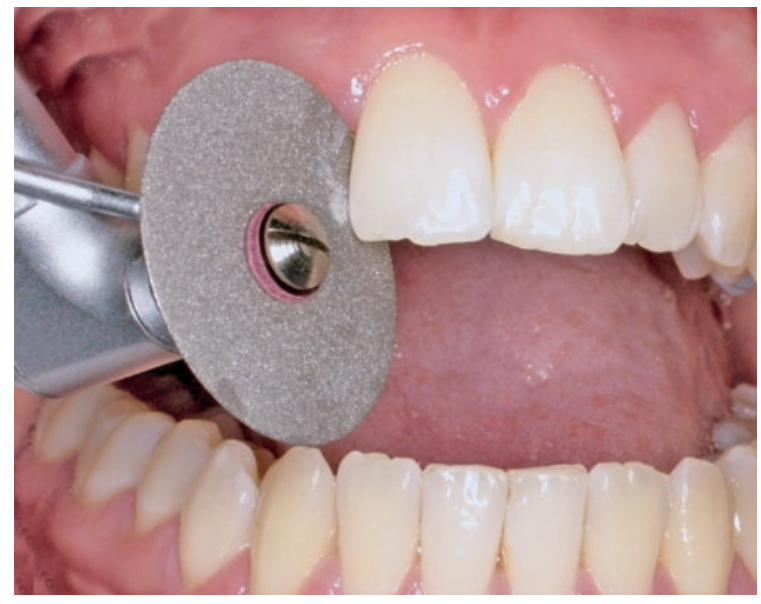

FIGURA 16 - Desgaste subseqüente da face distal do dente 11 com disco de aço de aproximadamente $0,25 \mathrm{~mm}$ de espessura.

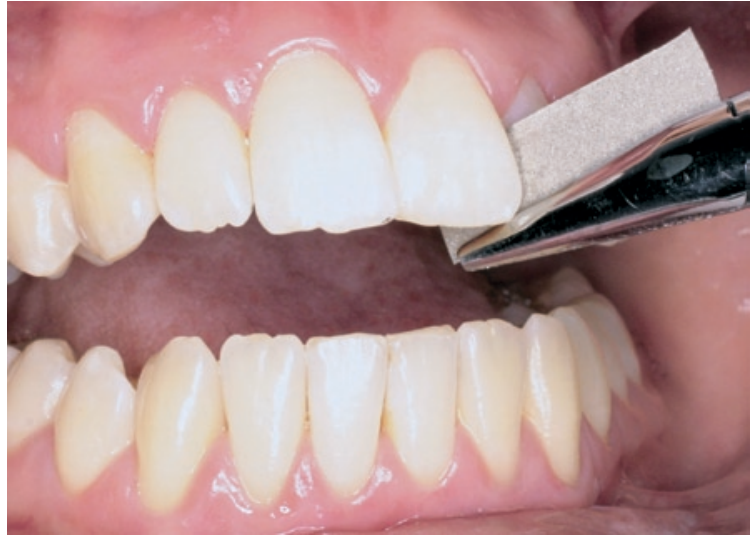

FIGURA 14 - Desgaste inicial na face distal do dente 21 com tira de lixa de $0,12 \mathrm{~mm}$ de espessura.

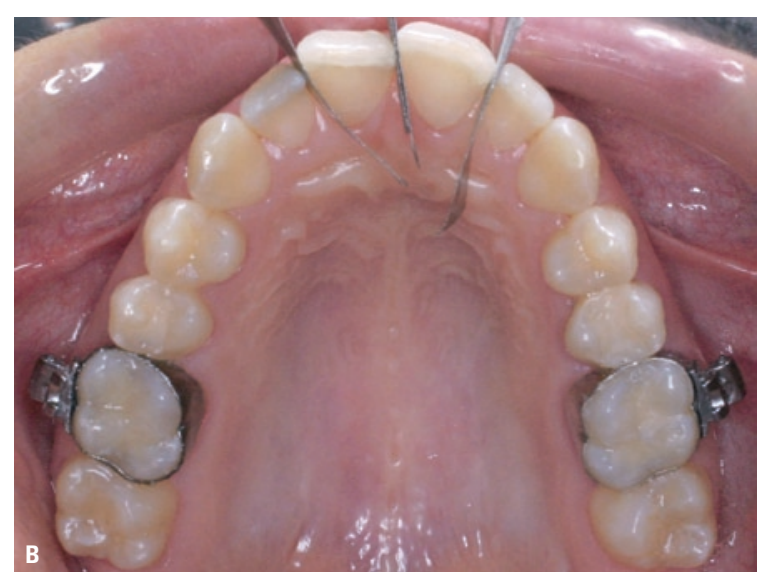




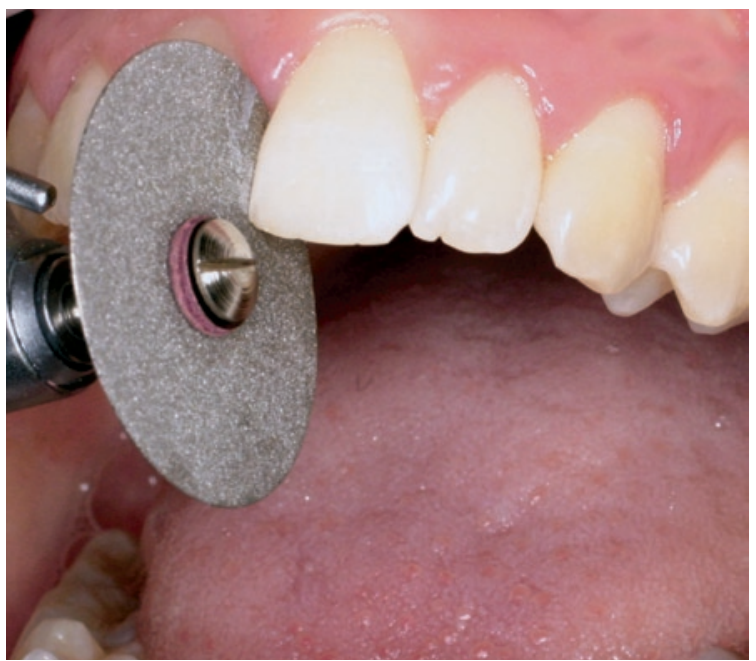

FIGURA 18 - Desgaste subseqüente da face mesial do dente 21 com disco de aço de aproximadamente $0,25 \mathrm{~mm}$ de espessura.

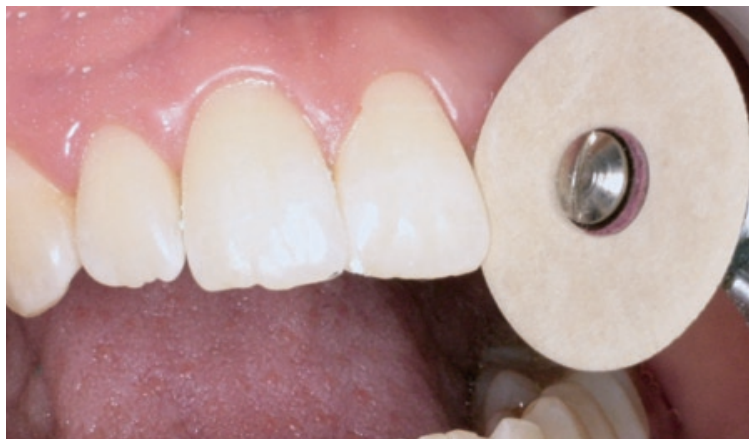

FIGURA 20 - Polimento realizado com discos Sof-Lex (3M-UNITEK).

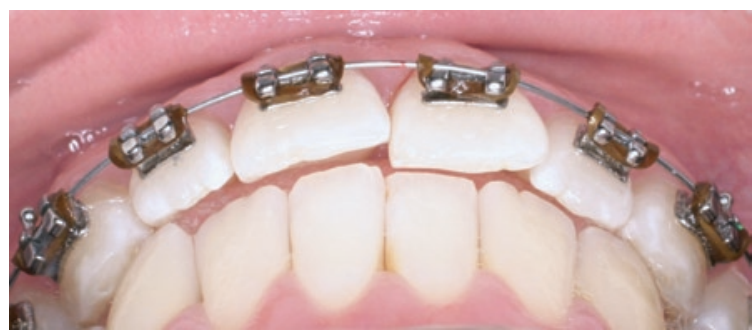

FIGURA 22 - Instalação do aparelho após o procedimento de desgaste proximal. Vista do trespasse horizontal na fase inicial do nivelamento.

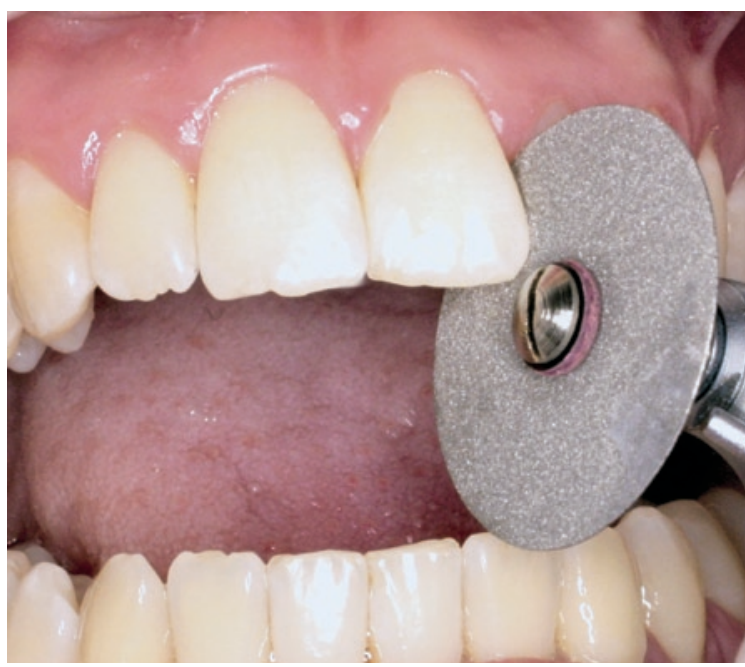

FIGURA 19 - Desgaste subseqüente da face distal do dente $21 \mathrm{com}$ disco de aço de aproximadamente $0,25 \mathrm{~mm}$ de espessura.

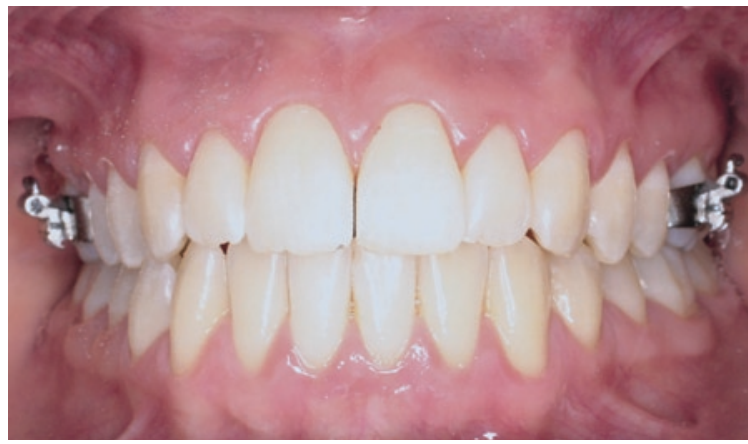

FIGURA 21 - Evidenciação do espaço obtido após o desgaste de aproximadamente $0,5 \mathrm{~mm}$ entre os dentes 11 e 21 , sendo $0,25 \mathrm{~mm}$ para cada face mesial.

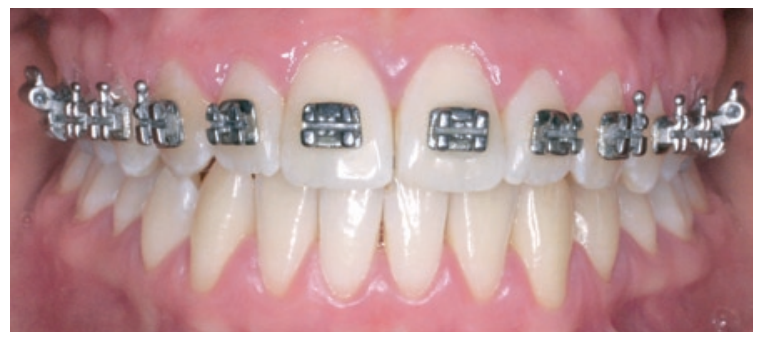

FIGURA 23 - Vista frontal intrabucal, após o término do nivelamento. 

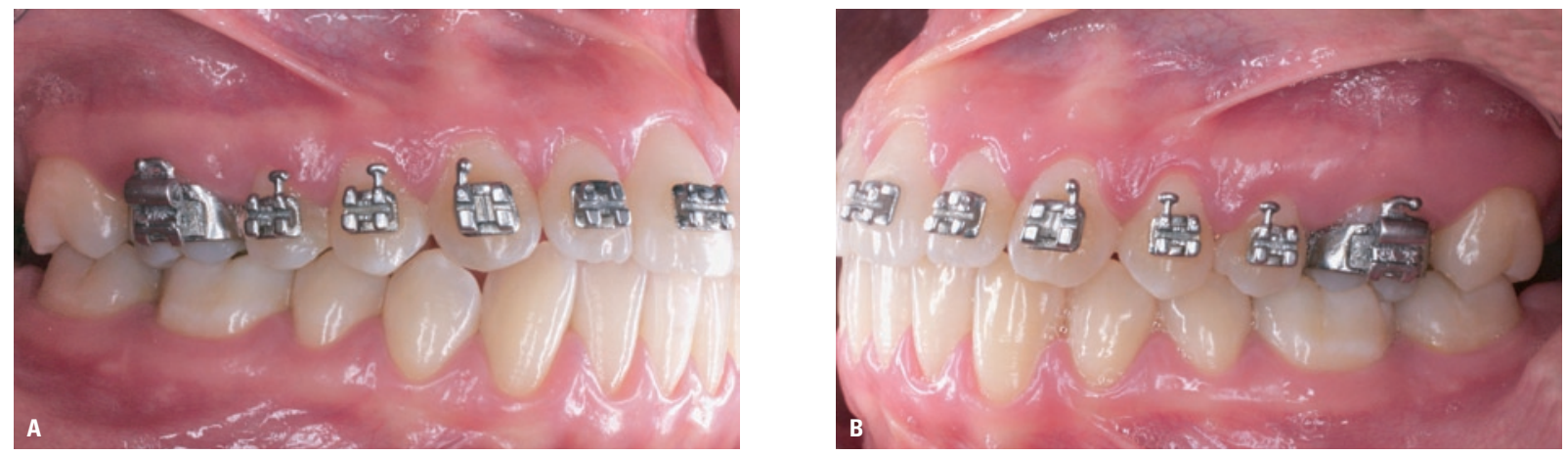

FIGURA 24 - Vistas laterais A) direita e B) esquerda, após o término do nivelamento.

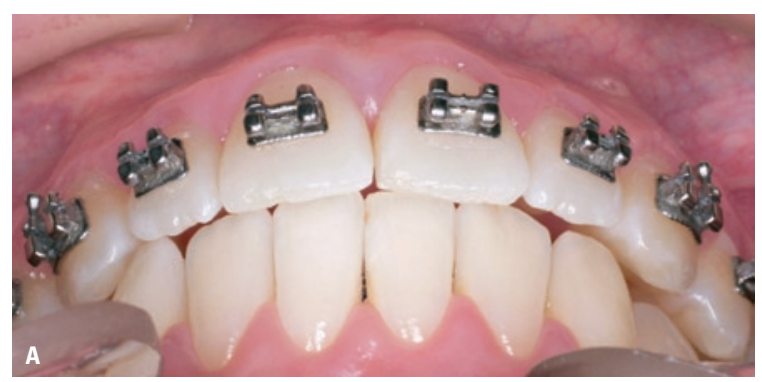

FIGURA 25 - A) Trespasse horizontal e B) vista oclusal do arco superior, evidenciando a eliminação da discrepância dentoalveolar negativa, após 0 término do nivelamento.
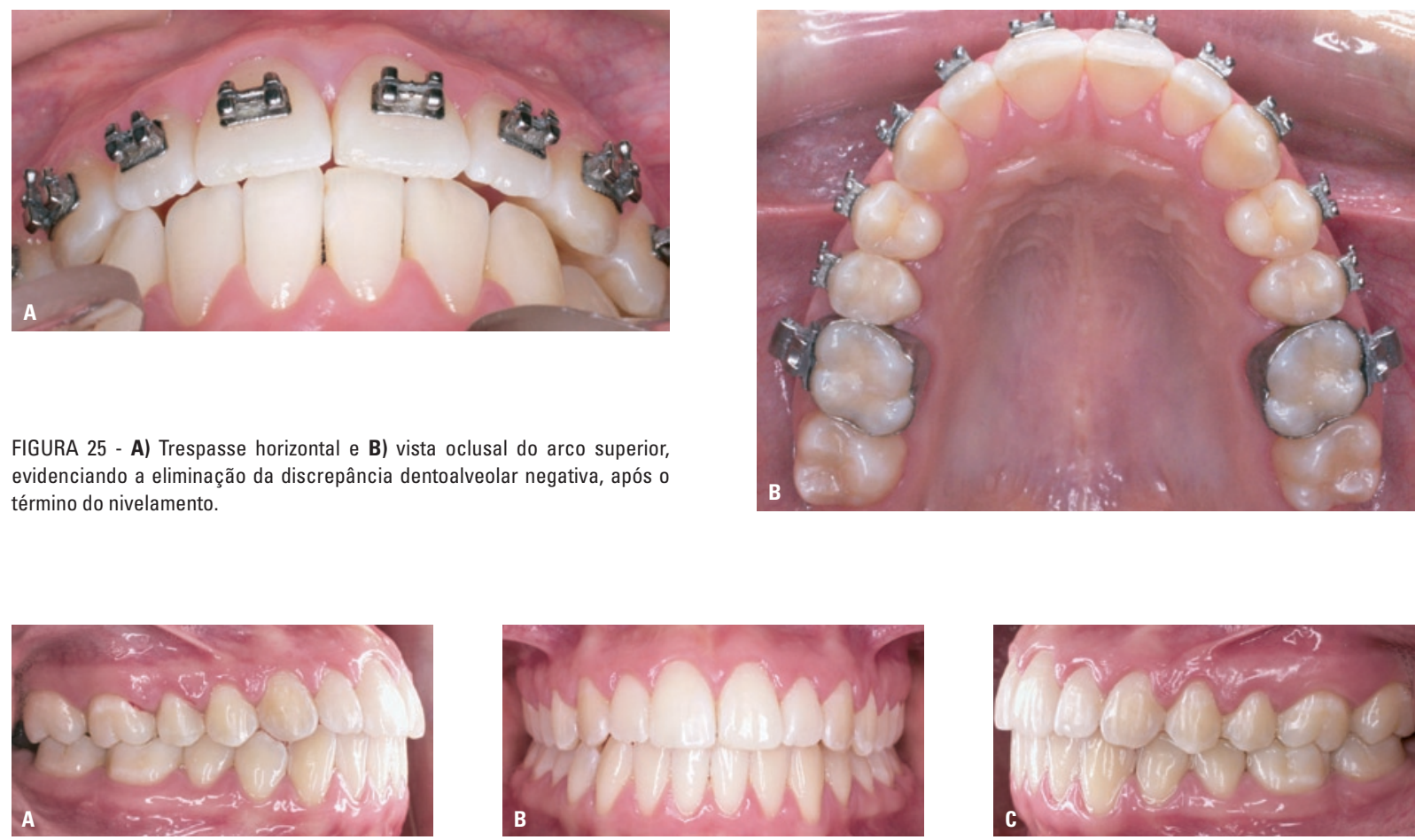

FIGURA 26 - Vista A) lateral direita, B) frontal e C) lateral esquerda, pós-tratamento.

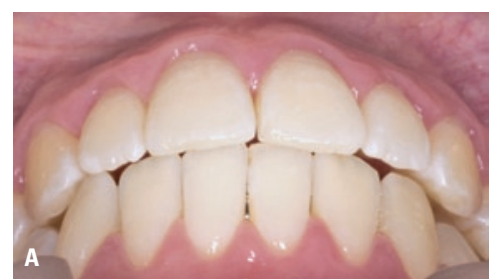

FIGURA 27 - A) Trespasse horizontal e B) vista oclusal do arco superior, evidenciando a eliminação da discrepância dentoalveolar, pós-tratamento.

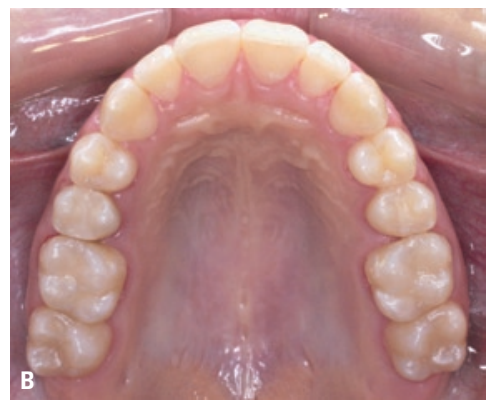

FIGURA 28 - Placa de Hawley para contenção.

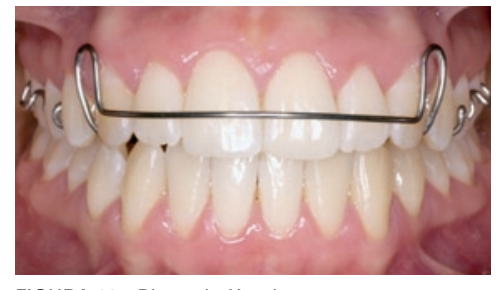



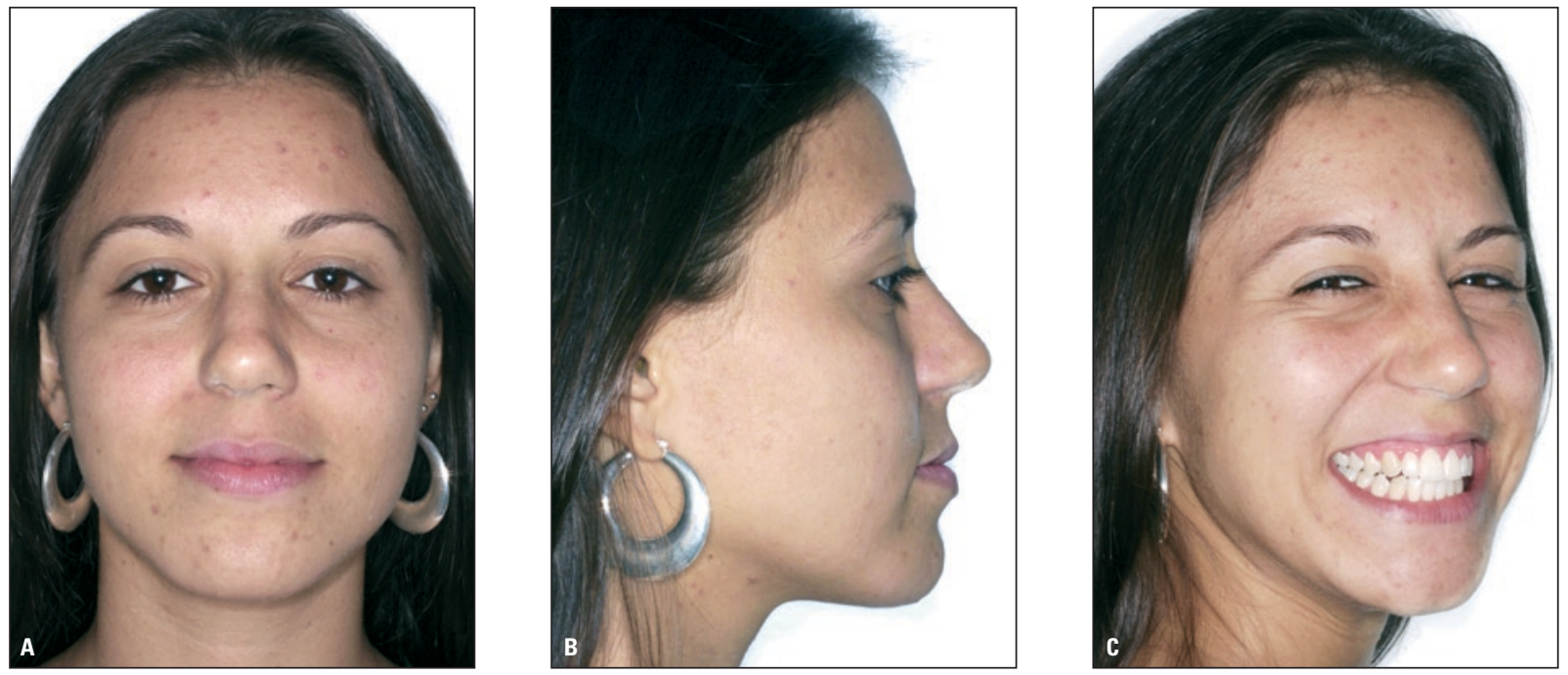

FIGURA 29 - Vistas faciais A) frontal, B) lateral e C) $45^{\circ}$ sorrindo, sem alterações faciais, pós-tratamento.
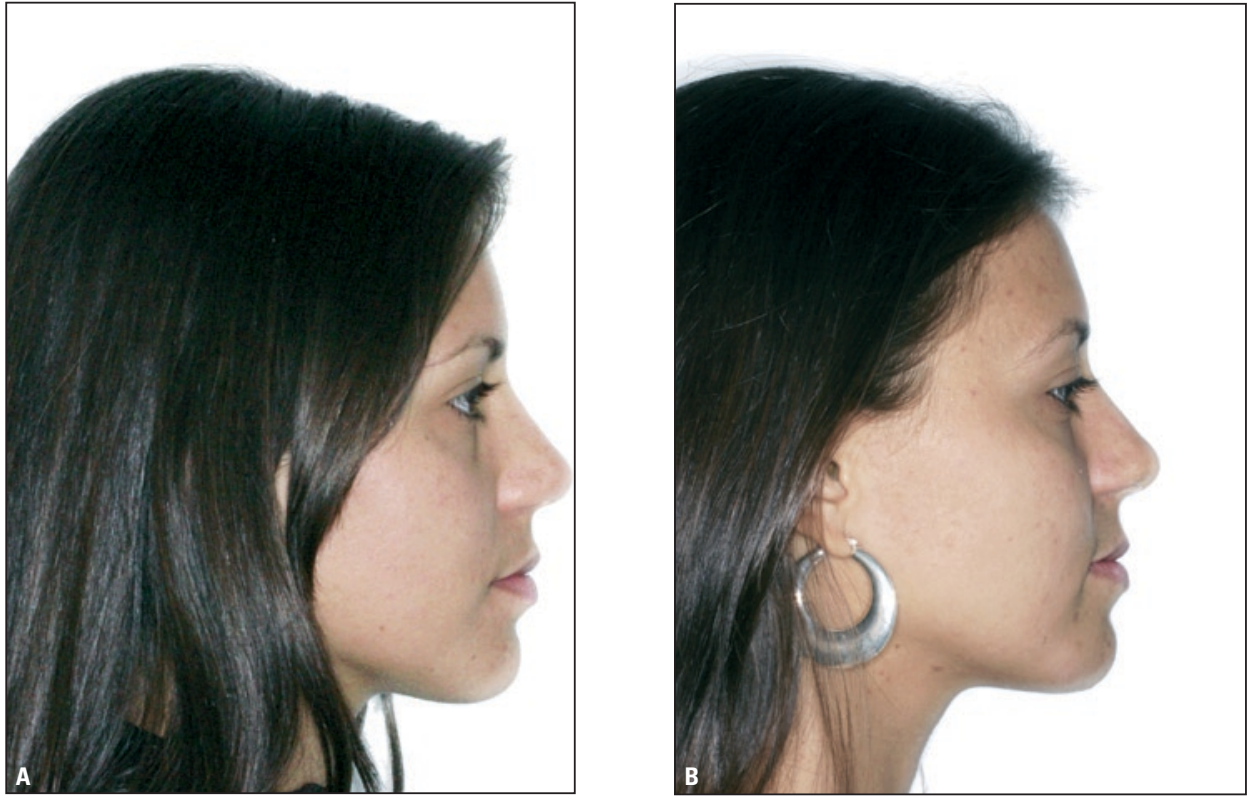

FIGURA 30 - Vistas faciais laterais A) pré-tratamento e B) pós-tratamento, evidenciando a manutenção das características faciais.
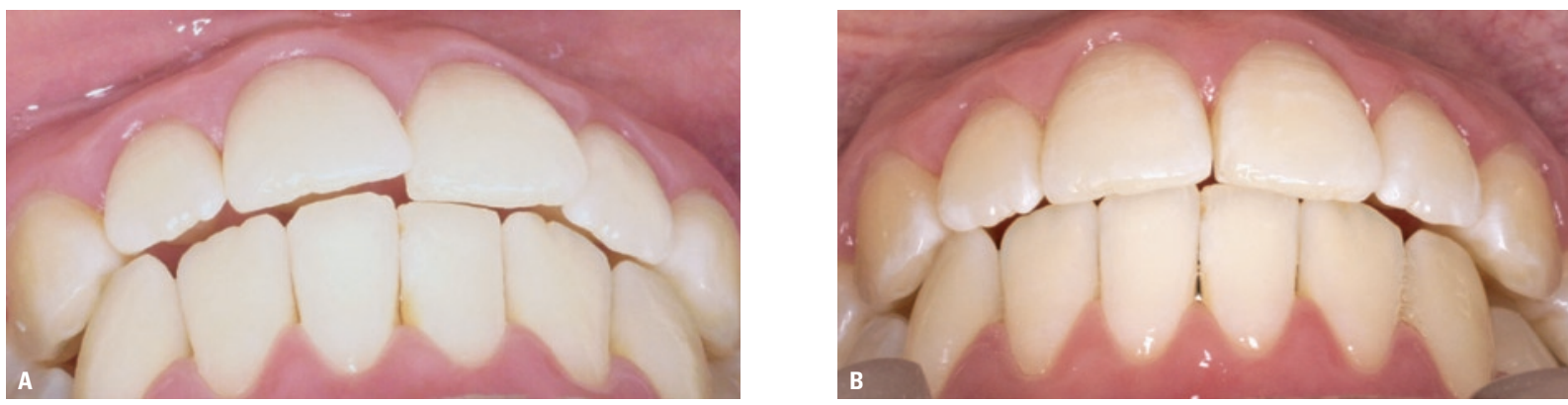

FIGURA 31 - Trespasse horizontal A) pré-tratamento e B) pós-tratamento. 


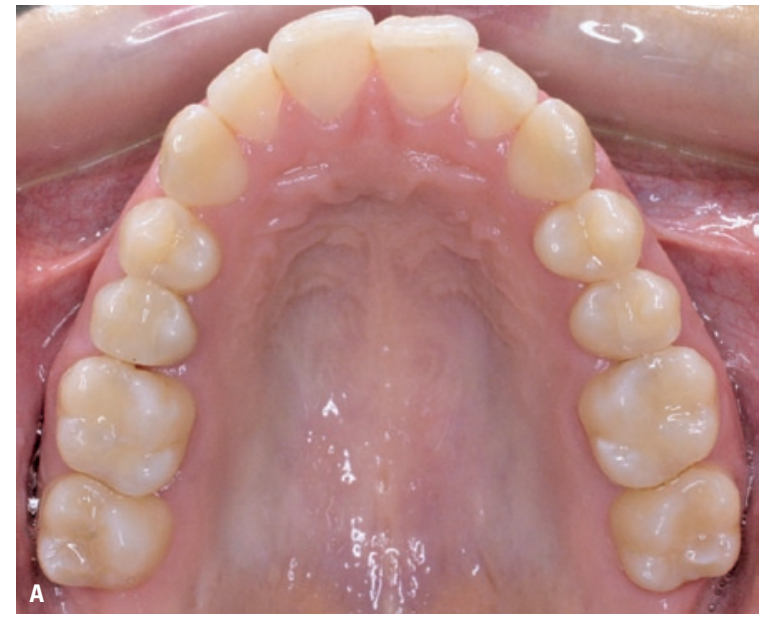

FIGURA 32 - Vista oclusal do arco superior: A) pré-tratamento e B) pós-tratamento.

\section{CONCLUSÕES}

O procedimento de desgastes interproximais pode ser realizado para correção da falta de proporcionalidade dentária, ou seja, casos que apresentam discrepância de Bolton. Além disso, constitui uma alternativa para os casos com apinhamentos moderados de até $2 \mathrm{~mm}$ para dentes anteriores e $4 \mathrm{~mm}$ para dentes posteriores, sendo $2 \mathrm{~mm}$ para cada hemiarco.

Independente da técnica utilizada para realização do procedimento, seja com tiras de lixa de aço, discos, pontas diamantadas ou brocas carbide, o fator diferencial para o sucesso do tratamento está na indicação correta e na execução de polimento com discos de polimento finos e ultrafinos após o desgaste, para diminuir as ranhuras provocadas pelo procedimento. Além disso, saliente-se

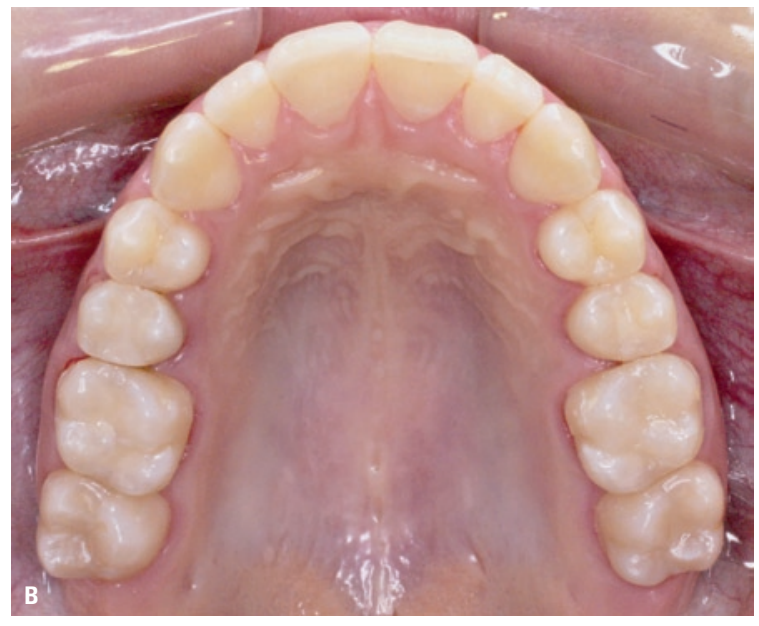

que a baixa susceptibilidade a cáries, assim como a higienização interproximal adequada, constituem fatores primordiais para a indicação dos desgastes.

A saúde dentária e periodontal podem ser preservadas por meio deste procedimento, desde que os limites biológicos sejam respeitados, o que implica em não ultrapassar o limite de aproximadamente $0,25 \mathrm{~mm}$ de desgaste em cada face de esmalte proximal dos dentes anteriores e $0,5 \mathrm{~mm}$ para os dentes posteriores. Este procedimento mantém uma espessura de esmalte aceitável biologicamente, resguarda a proporção mínima entre coroa e raiz no sentido mesiodistal e evita alterações periodontais em virtude da proximidade radicular inadequada.

\title{
Interdental stripping and it's clinical implications
}

\begin{abstract}
Background: A dental alignment and its stability are important objectives of the orthodontic treatment. The crowding in the anterior area is a common anomaly tooth position problem and, to obtain its correction, the clinical options to the orthodontist are extractions, expansion of dental arch, and dental stripping. Stripping are usually used but it is frequently questioned for the indications, techniques and conditions pre and post-treatment. Objective: The purpose of this article is to present a discussion, based in the pertinent literature, of the main factors related to this clinical procedure.
\end{abstract}

Key words: Interdental stripping. Crowding. Tooth movement. 


\section{REFERÊNCIAS}

1. AASEN, T. O.; ESPELAND, L. An approach to maintain orthodontic alignment of lower incisors without the use of retainers Eur. J. Orthod., Oxford, v. 27, p. 209-214, 2005.

2. ARTUN, J. et al. Long term effect of thin interdental alveolar bone on periodontal health after orthodontic treatment. J. Periodontol., Chicago, v. 57, p. 341-346, 1986

3. BARRER, H. G. Limitations in Orthodontics. Am. J. Orthod. Dentofacial Orthop., St. Louis, v. 65, no. 6, p. 612-625, June 1974.

4. BOLTON, W. A. Disharmony in tooth size and its relation to the analysis and treatment of malocclusion. Angle Orthod., Appleton, v. 28, p.113-130, 1958.

5. CORRUCCINI, R. Australian aboriginal tooth succession, interproximal attrition, and Begg's theory. Am. J. Orthod. Dentofacial Orthop., St. Louis, v. 97, no. 4, p. 349-357, Apr. 1990.

6. CROSBY D. R.; ALEXANDER, C. G. The occurrence of tooth size discrepancies among different malocclusion groups. Am. J. Orthod. Dentofacial Orthop., St. Louis, v. 95, p. 457-461, 1989.

7. DIPAOLO, R. J.; BORUCHOV, M. J. Thoughts on stripping of anterior teeth. J. Clin. Orthod., Boulder, v. 5, p. 510-511, Sept. 1971.

8. EL-MANGOURY, N. H. et al. In vivo remineralization after air rotor stripping. J. Clin. Orthod., Boulder, v. 25, no. 2, p. 75-78, Feb. 1991

9. FREEMAN, J. E.; MASKERONI, A. J.; LORTON, L. Frequency of Bolton tooth size discrepancies among orthodontic patients. Am. J. Orthod. Dentofacial Orthop., St. Louis, v. 110, p. 2427, 1996.

10. HARFIN, J. F. Interproximal stripping for the treatment of adult crowding. J. Clin. Orthod., Boulder, v. 34, no. 7, p. 424-433, July 2000

11. JOSEPH, V. P. et al. Orthodontic microabrasive reproximation. Am. J. Orthod. Dentofacial Orthop., St. Louis, v. 102, no. 4, p. 351-359, Oct. 1992

12. LITTLE, R. The irregularity index: a quantitative score of mandibular anterior alignment. Am. J. Orthod., St. Louis, v. 68, p. 554-563, 1975

13. PIACENTINI, C.; SFONDRINI, G. A scanning electron micros- copy comparison of enamel polishing methods after air-rotor stripping. Am. J. Orthod. Dentofacial Orthop., St. Louis, v. 109 , no. 1 , p. 57-63, Jan. 1996

14. RADLANSKI, R. J. et al. Plaque accumulations caused by interdental stripping. Am. J. Orthod. Dentofacial Orthop., St. Louis, v. 94, no. 5, p. 416-420, Nov. 1988

15. RADLANSKI, R. J. et al. Morphology of interdentally stripped enamel one year after treatment. J. Clin. Orthod., Boulder, v. 23, no. 11, p. 748-751, Nov. 1989.

16. ROGERS, G. A.; WAGNER, J. M. Protection of stripped ename surfaces with topical fluoride applications. Am. J. Orthod. St. Louis, v. 56, no. 6, p. 551-559, Dec. 1969

17. SHERIDAN, J. J. Air-rotor stripping. J. Clin. Orthod., Boulder, v. 19, p. $43-59,1985$

18. SHERIDAN, J. J. Air-rotor stripping update. J. Clin. Orthod. Boulder, v. 21, p. 781-788, 1987.

19. SHERIDAN, J. J.; LEDOUX, P. M. Air-rotor stripping and proximal sealants - an SEM evatuation. J. Clin. Orthod., Boulder, v. 23, p. $790-794,1989$

20. STROUD, J. L. et al. Enamel thickness of the posterior dentition: it's implications for nonextraction treatment. Angle Orthod., Appleton, no. 2, p. 141-146, 1998.

21. TUVERSON, D. L. Anterior interocclusal relations - Part I. Am. J. Orthod., St. Louis, v. 78, no. 4, p. 361-370, Oct. 1980

22. TWESME, D. A. et al. Air-rotor stripping and enamel demineralization in vitro. Am. J. Orthod. Dentofacial Orthop., St. Louis, v. 105, no. 2, p. 142-152, Feb. 1994.

23. VAN DER FEHR, F. R.; STEINESS, E. The solubility rate of unabraded, abraded, and exposed human enamel surfaces studied by means of activation analysis. Arch. Oral Biol., New York, v. 11, no. 2, p. 1405-1418, 1966

24. ZACHRISSON, B. U.; MJÖR, I. A. Remodeling of teeth by grinding. Am. J. Orthod., St. Louis, v. 68, no. 5, p. 545-553, Nov. 1975.

25. ZACHRISSON, B. U. Excellence in finishing. J. Clin. Orthod. Boulder, v. 20, p. 536-556, 1986

26. ZHONG, M. et al. SEM evaluation of a new technique for interdental stripping. J. Clin. Orthod., Boulder, v. 33, no. 5 p. 286-292, May 1999.
Endereço para correspondência

Osmar Aparecido Cuoghi

Faculdade de Odontologia de Araçatuba - UNESP

Rua José Bonifácio, 1193 Caixa Postal 341

CEP: 16.015-050 - Araçatuba/SP

E-mail: osmar@foa.unesp.br 